\title{
Compreendendo o estar com câncer ginecológico avançado: uma abordagem heideggeriana*
}

\author{
UNDERSTANDING WOMEN WITH ADVANCED GYNECOLOGICAL CANCER: \\ AHEIDEGGERIAN APPROACH
}

COMPRENDIENDO EL ESTAR CON CÁNCER GINECOLÓGICO AVANZADO: UNABORDAJE HEIDEGGERIANO

\section{Ana Regina Borges Silva', Miriam Aparecida Barbosa Merighi²}

\section{RESUMO}

A trajetória deste estudo voltouse para a compreensão da vivência das mulheres com câncer ginecológico avançado. Optou-se por uma pesquisa qualitativa com abordagem fenomenológica, com base na questão norteadora: "Gostaria que você me contasse a sua experiência; Como é ser mulher com câncer ginecológico?' Obtiveram-se seis depoimentos dos quais emergiram as unificações ontológicas analisadas e interpretadas, segundo o referencial filosófico de Martin Heidegger. Tais unificações permitiram vislumbrar caminhos para cuidar dessas mulheres que vão além do conhecimento técnico científico. É necessário compreender o vivido, assegurando um cuidar que contemple a subjetividade e intersubjetividade.

\section{DESCRITORES}

Enfermagem oncológica. Cuidados de enfermagem. Neoplasias dos genitais femininos.

\section{ABSTRACT}

This qualitative phenomenological research was carried out in order to understand how women experience living with advance gynecological cancer. We chose to make a qualitative survey in a phenomenological approach, based on the following directive question: "I'd like you to tell me your experience: 'How is it to be a woman with gynecological cancer?"' Six women were interviewed. The ontological unification which emerged from the speeches were analyzed and interpreted according to Martin Heidegger's philosophical referential. These unifications made possible to see ways to care for these women that go far beyond technical and scientific knowledge. It is necessary to understand what has been lived by the other, thus ensuring a quality of care that contemplates subjectivity and inter-subjectivity.

\section{KEY WORDS}

Oncological Nursing.

Nursing Care.

Genital neoplasms, female.

\section{RESUMEN}

La trayectoria de este estudio se orientó a la comprensión de la vivencia de las mujeres con cáncer ginecológico avanzado. Se optó por una investigación cualitativa con abordaje fenomenológico, con base en la pregunta norteadora: "Desaría que Ud. me contase su experiencia: ¿cómo es ser mujer con cáncer ginecológico?" Se obtuvieron seis discursos de los cuales emergieron las unificaciones ontológicas analizadas e interpretadas, según el referencial filosófico de Martin Heidegger. Tales unificaciones permitieron vislumbrar caminos para cuidar a esas mujeres que van más allá del conocimiento técnico científico. Es necesario comprender lo vivido, asegurando un cuidar que contemple la subjetividad e intersubjetividad.

\footnotetext{
* Texto extraído da Tese "Convivendo com o câncer ginecológico avançado: em foco a mulher e seus familiares", Programa Interunidades da

Escola de Enfermagem da Universidade de São Paulo (EEUSP)

e Escola de Enfermagem de Ribeirão Preto da USP, 2002.

1 Enfermeira. Professora

Doutora do Departamento de Enfermagem da Faculdade de Ciências Médicas da Universidade Estadual de Campinas (UNICAMP) anare@fmc.unicamp.br 2 Enfermeira obstetra. Professora Livredocente do Departamento Materno-

Infantil e Psiquiátrica da EEUSP.

merighi@usp.br
}

\section{DESCRIPTORES}

Enfermería oncológica. Cuidados de enfermería. Neoplasias de los genitales femeninos. 


\section{INQUIETAÇÕES E OBJETIVO DO ESTUDO}

O interesse em estudar a mulher com câncer ginecológico avançado, partiu da atuação de uma das autoras desse trabalho. Sua vivência profissional enquanto enfermeira, durante dez anos, em um serviço de oncologia ginecológica de uma universidade pública e, posteriormente, exercendo nesse local a docência em enfermagem, junto à disciplina Saúde da Mulher, possibilitou a oportunidade de conviver com mulheres portadoras de câncer, compartilhando com essas pessoas os momentos que experienciaram durante a doença e tratamento.

Dado ao interesse pelo cuidado de enfermagem a estas pessoas, particularmente quanto àquele dispensado às mulheres com doença em estadio avançado e, observando que as enfermeiras e os demais integrantes de sua equipe estavam mais preparados para atuar junto às mulheres internadas para tratamento cirúrgico ou com a doença sob controle, desenvolveu a dissertação de mestrado com o objetivo de compreender a vivência de enfermeiras no cuidar de mulheres com câncer ginecológico avançado ${ }^{(1)}$.

Esse estudo mostrou que a demanda de cuidado de enfermagem à mulheres com câncer ginecológico avançado repercute no desempenho das enfermeiras, tanto no âmbito técnico como no expressivo. $\mathrm{O}$ cuidado à estas pacientes foi considerado tarefa difícil devido ao confronto do profissional de enfermagem com as desfigurações corpóreas, a dor, a proximidade da morte, ao fato desse profissional possuir uma formação acadêmica insuficiente, conforme eles mesmos apontaram, e, ainda, às condições de trabalho serem insatisfatórias, demonstrando, assim, que não havia real interação entre a enfermeira e a paciente ${ }^{(1)}$.

Durante a realização deste estudo e da vivência com as mulheres, percebeu-se a pouca relevância dada pelo profissional de enfermagem no sentido de não considerar a experiência do câncer ginecológico avançado sob a perspectiva da mulher que vive esta situação.

A perplexidade referente às dificuldades descritas pelas enfermeiras no cuidar de enfermagem a estas mulheres, no tocante aos aspectos relacionais, à formação acadêmica insuficiente na realização deste tipo de cuidado e às adversas condições de trabalho, assim como a vivência junto a estas pacientes, ora cuidando ora atuando com os alunos de graduação, ampliaram as inquietações a respeito desta temática, despertando as seguintes indagações: Como é para estas mulheres conviverem com uma doença crônica grave permeada por estigmas e mitos? Qual é o sentido que atribuem às suas vidas diante desta experiência de adoecimento?
Ao ingressar no Curso de Doutorado, pareceu conveniente delimitar o estudo focalizando mulheres que vivenciassem o câncer ginecológico, especificamente as que possuíssem a doença em estadio avançado e cuja localização primária fosse o colo uterino, o corpo de útero ou os ovários, pois durante o exercício das suas atividades, assistencial e docente, percebia que existem momentos no decorrer do tratamento em que as mulheres apresentavam necessidades físicas e emocionais diversas relacionadas à convivência com a doença e seu tratamento.

Diante do fato de que as mulheres com câncer ginecológico avançado apresentam uma variedade de problemas e dada a insatisfação com o cuidado de enfermagem que tem sido prestado e ensinado, percebe-se que a situação é complexa, pois envolve saberes que vão além do domínio técnico-científico. Na busca de um cuidado humanizado, pensamos como seria este cuidar em enfermagem que considere não apenas a doença da mulher, numa visão biologicista, mas que incorpore as experiências vivenciadas pela paciente.

Assim sendo, desenvolvemos o presente estudo com o objetivo de compreender a vivência das mulheres com câncer ginecológico avançado ou seja, desvelar o fenômeno ser-mulher com câncer ginecológico avançado, buscando compreender as questões vivenciadas por estas mulheres.

\section{APRESENTANDO 0 REFERENCIAL METODOLÓGICO}

Devido à natureza das inquietações anteriormente apresentadas, percebemos que a abordagem qualitativa era o caminho mais coerente para conseguir compreender o significado da experiência vivida pela mulher, pois o foco de atenção da pesquisa qualitativa está direcionado para o específico, o particular, o individual do fenômeno, procurando, assim, compreendê-lo.

O estudo da narrativa dos clientes proporcionado pela pesquisa qualitativa, em especial na área de conhecimento da Enfermagem, possibilita entender melhor a subjetividade da clientela assistida, bem como oportuniza conhecer o significado de sua vivência no processo saúde-doença, o que se reflete na assistência oferecida pelo enfermeiro ${ }^{(2)}$.

O sentido da existência, a razão de ser da vida humana, o amor, a angústia, o desespero, a felicidade, a autenticidade, o acolhimento merecem uma meditação filosófica de natureza compreensiva, explicativa e interpretativa. A dimensão subjetiva é preponderante em relação à objetiva. Não se pode converter o homem em objeto de nosso manuseio, controle, dominação. O homem é sempre sujeito, nosso semelhante. A ênfase dada nesta perspectiva é encontrada na fenomenologia a partir do seu movimento contemporâneo com Edmund Husserl ${ }^{(3)}$. 
A fenomenologia possibilita ao pesquisador o acesso à consciência humana, isto é, a volta às coisas mesmas, às essências, o que significa chegar à verdade, à realidade desprovida de estereótipos, estigmas, ou seja, abandonar os preconceitos e pressupostos em relação ao fenômeno interrogado ${ }^{(4)}$.

Tendo em vista que a fenomenologia visa compreender a existência do ser humano e uma vez que a tendência da enfermagem é retomar e considerar o homem em sua totalidade existencial, acreditamos ser possível voltar nosso olhar para a mulher com câncer ginecológico avançado enquanto ser-situado-no-mundo, cabendo a elas desvelarem o sentido desta experiência. Por meio dos discursos obtidos, pretendemos compreender o não mostrado, o mundo-vida de cada uma, buscando a essência do fenômeno vivenciado por estas pessoas.

Pensando na mulher com câncer ginecológico avançado e o impacto do mesmo sobre ela, vislumbramos na ontologia existencial de Martin Heidegger a possibilidade de compreensão de alguns aspectos do ex-sistir destas pessoas, que são seres-lançados-no-mundo no qual convivem e compartilham experiências, pois nenhuma pessoa ex-iste se não for com algo ou com alguém, isto é, ex-sistencial do Ser.

\section{PERCORRENDOO CAMINHO METODOLÓGICO}

A região de inquérito(a) ${ }^{(a)}$ região ontológica, neste estudo, foi a própria situação na qual os fenômenos ocorrem, ou seja, o mundo-vida, o pré-reflexivo de cada mulher que vivencia e sofre a influência do câncer ginecológico avançado em seu cotidiano. Mundo este em que vivenciam suas experiências, relacionam-se e interagem com diferentes pessoas em graus variados de intimidade.

Neste sentido, ao constituir a situação da pesquisa, dirigimos nossas inquietações às descrições das mulheres com câncer ginecológico avançado, sujeitos deste estudo, nas quais os fenômenos se localizam, para aproximar-nos das experiências vivenciadas por elas, no intuito de que os fenômenos se manifestassem e se desvelassem em direção ao ser-mulher-com-câncer.

Desse modo, decidimos realizar a pesquisa com as mulheres portadoras de câncer ginecológico avançado que são clientes de um Serviço de Oncologia, pertencente a um hospital-escola, instituição pública, localizada no interior do Estado de São Paulo. Escolhemos esta instituição porque

\footnotetext{
(a) Região de inquérito é a região de perplexidade, o local transparente de minhas preocupações, enquanto pesquisador, onde é possível determinar aquilo que deve ser feito. Portanto, não é um espaço, mas um contexto conceitual onde as pessoas agem. In: Merighi MAB. Docência de enfermagem em uma Universidade Pública - um enfoque fenomenológico. São Paulo: EEUSP; 1993.
}

tem sido o cenário de muitas das inquietações e é um dos locais onde uma das autoras desempenha suas atividades de docência e assistência em enfermagem.

Elegemos como critérios para participar desta pesquisa as mulheres com câncer ginecológico avançado, localizado no colo uterino, corpo de útero ou ovários, cientes do diagnóstico, com idade acima de 18 anos e que concordassem em participar deste estudo, uma vez que, tanto no exercício da docência, como no desempenho das atividades assistenciais, neste local, optamos por cuidar das mulheres com câncer avançado, ou seja, daquelas que possuam um tumor maligno localmente avançado, em estadio IIIlb ou qualquer situação com metástases, estadio IV, ou com tumores, anteriormente tratados e recidivados ${ }^{(5)}$.

Ao definirmos nossa região de inquérito, não consideramos profissão e nível de escolaridade e, sim, o próprio contexto de vida de cada mulher, uma vez que o nosso interesse era a experiência vivida pelos sujeitos. Entretanto, um critério de inclusão que consideramos fundamental foi o de que os sujeitos possuíssem preservada sua capacidade cognitiva, ou seja, capacidade de entendimento, bem como sua habilidade em produzirem pensamentos lógicos e de expressarem-se com clareza, uma vez que as entrevistas seriam gravadas.

Após enviar o projeto deste estudo à Comissão de Pesquisa e ao Comitê de Ética em Pesquisa da instituição e obter o consentimento para a realização do mesmo, com a finalidade de conduzir-nos à região de inquérito, em um primeiro momento, iniciamos uma seleção dos prováveis sujeitos. Esta seleção deu-se por intermédio da nossa atuação nas unidades de internação e ambulatorial. Após essa seleção prévia, efetuava-se uma consulta ao prontuário dessas clientes.

Ao efetuar o convite e explicitar-lhes o objetivo da pesquisa, asseguramo-lhes o direito de não participar, caso não o desejassem. Esclarecemos que as entrevistas seriam identificadas com nomes fictícios, gravadas em fita cassete e que os dados seriam utilizados como fonte de conhecimento científico.

Nossas participantes nesta pesquisa, portanto, foram seis mulheres com câncer ginecológico avançado. Tendo em vista a natureza desta pesquisa, o número de pessoas consideradas como sujeitos participantes não foi estipulado anteriormente, mas determinado no transcorrer das entrevistas, em função de seus conteúdos, ou seja, a partir do momento em que percebia que os discursos mostravam-se suficientes para responder às interrogações e, assim, desvelar os fenômenos. Desta forma, o número de sujeitos participantes deste estudo foi definido por suas próprias descrições.

A coleta foi realizada por meio de entrevistas, previamente agendadas com as mulheres no período de fevereiro a 
junho de 2001. Procuramos criar um ambiente favorável para que a mulher pudesse falar livremente sobre o assunto, entretanto, a cada início, esclarecíamos, novamente, sobre os objetivos do estudo e apresentávamos o termo de consentimento, para que a participante lesse e assinasse o mesmo. Com estes procedimentos, cumprimos o que preconiza a Resolução 196/96 do Conselho Nacional de Saúde sobre pesquisa envolvendo seres humanos.

Iniciamos as entrevistas individualmente em local privativo. A maior parte dessas entrevistas foi realizada na instituição hospitalar, enquanto duas ocorreram na residência das participantes por solicitação das mesmas. Para obter a descrição da experiência da mulher que estava vivenciando o câncer ginecológico avançado partimos da seguinte questão norteadora: Gostaria que você me contasse a sua experiência. Como é ser mulher com câncer ginecológico?

Para efetuar a análise dos dados obtidos utilizamo-nos dos procedimentos preconizados por Josgrilberg ${ }^{(6)}$. Primeiramente, foram realizadas várias leituras de cada um dos discursos, buscando em cada um a presença de algumas das estruturas fundamentais da existência, delimitando as unidades de sentido conforme recomenda o autor anteriormente citado. Em seguida, efetuamos uma categorização prévia das unidades de sentido realizando uma seleção fenomenologicamente orientada das unidades mais relevantes de cada um dos discursos para a elucidação dos fenômenos. Finalmente, as unidades de sentido contidas nos discursos foram agrupadas e relacionadas entre si, sem deixar de indicar os momentos que são específicos na narração de cada fala, interligando os sentidos que foram desvelados pelos sujeitos. Por meio desse agrupamento das unidades de sentido emergiram as unidades temáticas, denominadas de Unificações Ontológicas que foram: A Relação do Dasein $^{(b)}$ na Vivência do Câncer; O Caminho da Transcendência da Mulher diante do Câncer; Vivenciando a Ambigüidade da Solicitude; Presença da Angústia decorrente de Estar-com Câncer.

\section{CONSTRUINDO OS RESULTADOS}

\section{A Relação do Dasein na Vivência do Câncer}

Compreender a mulher com câncer ginecológico avançado sob uma visão fenomenológica é buscar apreendê-la em um mundo circundante e no seu relacionamento com outros entes humanos e consigo mesma. Assim, os discursos das mulheres desvelaram o seu modo de ser-no-mundo ao vivenciarem a experiência de ter câncer ginecológico avançado, como manifestado a seguir:

(b) Em ser e tempo, Heidegger ${ }^{7}$ evoca o termo Dasein, que significa ser-ai, que se compõe de sein (ser) e da (ai), que significa presença; é aquilo que é, e ao, mesmo tempo, é o modo de ser, sua maneira de ser em sua cotianeidade.
[...] Pensei até que ia operar, ficar magra. Engordei muito [...] isso foi muito difícil. [...] "- Ah, deixa engordar! Não esquenta com isso não". Vou cuidar da saúde, do câncer em si. Que se dane a gordura. Não é que se dane a gordura, me fez mal... [...] eu nunca tive este peso. Perdi todas as minhas roupas. Eu me senti mal. [...] Eu sempre convivi com meus... 50 quilos [...] (Sol)

Pode-se perceber, neste relato, que tanto as manifestações corpóreas advindas do câncer como as reações da mulher, diante desta doença, são diversas, e não são excludentes nas mudanças que foram assinaladas como excesso. No caso do corpo, ou por ganho de peso ou por perda, não há perspectiva imediata para essas mulheres de onde irão chegar. Independente de o corpo ser estrutura, ele pertence à mulher inserida no mundo. A mulher que tem um corpo com câncer está em relação consigo mesma, enquanto corporeidade e temporalidade.

[...] emagreci muito... Perdi muito peso [...], eu pesava cerca de 65 quilos... Devo estar agora... se tiver com 50 quilos é muito. [...] A única coisa que eu perdi foi as roupas, que as roupas ficaram largas, eu tive que apertar... arrumar, mas agi como se fosse uma coisa normal. [...] Porque eu estava bem gorda, forte, não sei o que é sofrer. [...] É, eu estou muito frágil... [...] estou fraca, bem frágil... bem frágil, emagreci muito. (Neide)

No imaginário da fala de Neide reside a idéia de que o emagrecimento, ou seja, a caquexia é o próprio símbolo de quem está com câncer. Quando se fala ou se pensa em um doente com câncer, a figura que vem à mente das pessoas é de uma pessoa com o corpo deteriorado, caquético, fragilizado.

O corpo é intrínseco à pre-sença, pois, enquanto um serno-mundo relaciona-se com os entes que encontra e que a ele se apresentam, é por intermédio do corpo que se estabelecem condições para que esta relação se dê. Entretanto, apesar de ser uma condição necessária para essa relação, o corpo não é o suficiente, pois a senso-percepção desempenha um papel importante ${ }^{(7)}$.

[...] eu fiquei careca [...] na época em que eu fiquei carequinha fiz uma tatuagem, pus uma roupa super bonita e fui apresentadora de um troféu em minha cidade [...] mesmo 'tando careca'. [...] eu nunca vim aqui desarruma$\mathrm{da}$, eu tenho que vir arrumada, eu tenho que ficar bonita, porque eu vou ficar com cara de doente... eu não sou doente, eu não me vejo doente... eu só sei que eu tenho um câncer, mas a minha vida é normal [...] Eu não tenho... eu não sinto dor, eu não tenho... eu não sinto a doença [...] Então p'ra mim é meio que complicado isso. Eu não sinto a doença. [...] tenho uma vida normal, uma pessoa superatleta, uma pessoa animada, alegre... [...]. (Mara)

A mulher, sendo um ser-com, na vigência de modificações corpóreas, fecha-se em seu mundo por não conseguir conviver com as mesmas. Ser-com é uma característica existencial da pre-sença. O ser-só é um modo deficiente do ser-com ${ }^{(7)}$. 


\section{O Caminho da Transcendência da Mulher diante do Câncer}

A mulher quando demora a processar sua cura interna, permanece na de-cadência que diz respeito a sua própria desorganização interna de ser, criando barreiras para compreender o que está acontecendo consigo e velando as possibilidades para recriar o seu mundo. Consegue transcender a sua situação imediata, pois o seu existir não compreende somente o que é e está experienciando em dado instante, mas as múltiplas possibilidades para as quais a sua existência encontra-se aberta.

[...] Hoje eu posso dizer uma coisa: o câncer, não me impede de nada. A dor, a radioterapia, o mal-estar... A cabeça alguma vez já... Mas hoje em dia, não. O que eu quiser, realmente... Hoje em dia, o que eu me propor a fazer... Dá p'ra fazer ginástica, dá p'rá sair... dá p'ra curtir. [...] comecei a fazer hidroginástica... e 'tá dando certo'. São conquistas. Você vai conquistando caminhos. Cada coisa, cada barreira desta que você vence, cada pedacinho mínimo às vezes... tem valor [...]. (Sol)

[...] Se for preciso fazer quimioterapia, vou... vamô fazer, vai cair cabelo... vai nascer de novo. Seja o que Deus quiser. Eu 'Tô pronta p'ra tudo. Tem uma força... muito grande dentro de mim. (Neide)

Nesta trajetória convivendo com o câncer ginecológico avançado, a mulher tem a possibilidade de voltar-se para si mesma como ser possível em sua propriedade e alcançar o seu poder-ser e a responsabilidade do seu ser lançado-nomundo. A mulher assume-se como ser que se empenha para tratar de sua doença assumindo a terapia como parte intrínseca do seu processo para poder transcender.

Com relação ao tratamento eu... tinha muito medo do tratamento. Falam muito do tratamento. É, não é brando não. Mas... tem a quimio... mas tem gente que sofre um acidente passa momentos piores do que eu passo com a quimioterapia... dá p'ra levá [...] Fiz braqui. Eu tive que fazer radio depois. [...] A braqui era... tenebrosa... Eu começava até a marchar quando chegava do lado de fora (risos). Porque aí... eu sei dizer que... a gente precisa de força [...]. (Mara)

\section{Vivenciando a Ambigüidade da Solicitude}

Durante as entrevistas as mulheres mencionaram, também, que receberam apoio de familiares, amigos, profissionais e de outras pessoas significativas para enfrentarem a experiência de adoecimento.

[...] Mas depois eu fui à casa do meu pastor, falei p'rá a esposa dele, foi onde ela me deu muita força, começou a conversar comigo... foi aonde que eu... 'tô conseguindo superar...[...]. (Sil)

[...] A minha família é super compreensiva, todos me deram apoio, meus filhos, nora, todos... todos [...] a minha família eu não tenho queixa recebi apoio de todo mundo, daqui do hospital principalmente, todo mundo aqui, que eu já conheço de cara...'tô aqui já há quase três anos, todas as enfermeiras, médicos [...] Pela minha família, principalmente, meu filho. (Neide)

Ser-mulher-com-câncer-ginecológico avançado revelou, também, que na vida cotidiana as mulheres percebem-se como pessoas diferentes das outras, pois recebem por parte delas um tratamento diferenciado. Logo, observa-se pelas falas abaixo transcritas que o comportamento dos "outros" influencia em seu modo de ser:

Outra coisa difícil, também, é... você começa a ser tratada diferente pelas pessoas. Embora seja com carinho você é tratada diferente. Desde o momento do diagnóstico do câncer, você é uma pessoa diferente [....]. (Sol)

[...] não sei parece que a gente não é a mesma coisa que as outras pessoas. Parece que a gente é diferente... parece que é diferente a situação...ninguém chora perto de você, ninguém nossa, mas... a gente sabe que no fundo, no fundo não é assim. (Sil)

Os depoimentos anteriores desvelam a solicitude (preocupação) que enquanto caráter ontológico do ser-com pode encontrar-se em seus modos positivos, que possui duas possibilidades extremas. A solicitude pode retirar o cuidado do outro e tomar-lhe o lugar nas ocupações, substituindo-o em um modo de solicitude que se antepõe. A solicitude está guiada pela consideração e pela tolerância.

Comumente a mulher desempenha na família um papel de cuidadora de seus membros, no entanto, por ocasião do adoecimento, há um processo inverso e ela necessita adaptar-se a sua nova condição, pois, normalmente passa a ser cuidada.

Ocupar-se da alimentação e vestuário, bem como tratar do corpo doente, é preocupação. O ser por um outro é um modo possível de preocupação independente do estado em que o outro se encontra. Enquanto ser-com, a pre-sença $e ́$, essencialmente, em função dos outros. Mesmo quando cada pre-sença não se volta para os outros, quando acredita não precisar deles ou quando os dispensa, ela ainda é no modo de ser-com. No ser-com, enquanto o existencial de ser em função dos outros, os outros já estão abertos em sua pre-sença ${ }^{(7)}$.

A mulher pode passar a acolher a doença, ou seja, familiarizar-se com a mesma que passa a fazer parte do seu ser, conforme desvela o discurso abaixo.

[...] fiquei internada fevereiro inteiro... foi assim... dor... acho que foi o pior, mas depois normalizou... não tive mais nada, foi a fase mais crítica que eu passei... A minha vida é normal... tá ótimo. Pelo menos tô aqui, não é? (risos). Ah, se operar vou ter que tirar esta bacia. Não esquenta não, a gente compra uma de $\mathrm{R} \$ 1,99$ e encaixa (risos). Não tem jeito, é uma coisa que eu tenho que conviver mesmo. (Rosa) 
Esta fala retrata a presença de uma preocupação velada com sua condição que distancia esta mulher da própria concretude ampliada de sua realidade, mostrando sentimentos ambíguos dentro de si. Este distanciamento de si mesmo, em relação a dor causada pela doença, propicia o estarcom o vazio que será abordado no próximo item.

\section{Presença da angústia decorrente de estar-com câncer}

As mulheres com câncer ginecológico vivenciam uma experiência que envolve perdas, medo, tristeza, que, em alguns momentos, pode ser percebida como sem resolução. É um fato presente em seu cotidiano o medo da recidiva tumoral, pois o surgimento de dores ou de qualquer alteração em seu estado físico representa este fantasma e rememora que a doença pode estar progredindo. É o que verbaliza Neide:

[...] A gente vê... Quem está na chuva é p'ra se molhar, como diz. Então a gente 'tá sabendo, você 'tá... a gente vê cada caso aí, horrível. Começa a se alastrar, pegar outros órgãos, a gente vê cada caso aí, horrível. Começa a se alastrar, pegar outros órgãos, a gente vê que tem gente que tem no seio, daí a pouco 'tá no pulmão [...] Eu tenho muito medo.[...] eu só peço a Deus é isso, mas eu tenho certeza que comigo não vai acontecer isso, tenho certeza de que eu vou ficar boa, que Deus vai me curar. Que não vai sair dali. (Neide)

O temor é um modo da disposição não permanente, um modo de ser da mulher que, ao sentir dores, de origem cancerosa, vivencia-a como uma ameaça à vida. A mulher interpreta a dor como um sinal de alerta de seu corpo, que pode estar assinalando-lhe que a doença pode estar "migrando" de seu local de origem, espalhando-se por seu organismo, dificultando a possibilidade de ser curada e conseqüentemente levando-a morte.

Na medida em que uma ameaça subitamente abate-se sobre o ser-no-mundo da ocupação, o temor se transforma em pavor. Desse modo, deve-se distinguir na ameaça: a aproximação mais próxima do que ameaça e o modo de encontro com a própria aproximação, o súbito ${ }^{(7)}$.

Como a angústia já sempre determina o ser-no-mundo, este, enquanto ser que vem ao encontro na ocupação junto ao "mundo", pode sentir temor. Temor é angústia imprópria, entregue à de-cadência do "mundo" e, como tal, angústia nela mesma velada ${ }^{(7)}$.

É o medo que acaba por dominar o cotidiano destas mulheres. Neste sentido, outra colaboradora, no depoimento a seguir, referindo-se ao receio da recidiva, reforça o que foi exposto com relação ao medo de deixar de viver:

[...] Este revertério que deu por causa deste agulhamento que eu fiz [...] tive que ser internada, então o intestino parou, deu problema no ânus... eu estava com medo que fosse uma... um segundo tumor, graças a Deus a biópsia constatou que não é. [...] que eu já estou mais feliz. Nos primeiros dias que eu internei eu fiquei apavorada... [...] mas de repente surgiu esta dor [...] Como a gente já tem a doença... dizem que a doença vai espalhando aos poucos, eu fiquei assustada [...]. Deus queira que... seja só isso. Eu tenho um pouco de medo. Tenho um pouco de medo. A gente vê... Quem está na chuva é p'ra se molhar, como diz. Então a gente 'tá sabendo, você 'tá... a gente vê cada caso aí, horrível. Começa a se alastrar, pegar outros órgãos, a gente vê cada caso aí, horrível. Começa a se alastrar, pegar outros órgãos, a gente vê que tem gente que tem no seio, daí a pouco 'tá no pulmão [...] Eu tenho muito medo. (Neide)

Apesar da morte fazer parte da vida e do ser humano ter consciência de que é mortal, ela, geralmente, apresenta-se como um acontecimento longínquo e que só acontece com os outros e não consigo mesmo. Este fato está presente no diagnóstico de uma doença grave, crônica e que possui um estigma, como é o caso do câncer, que é relacionado com questões que podem causar profundas modificações na vida pessoal.

Adoecer por câncer recorda que se é um ser-para-amorte, ou seja, "a gente também morre no final". A morte é a possibilidade que está sempre a nossa frente. A morte encontra-se dentro de nossa vida, uma vez que sabemos de nosso morrer. É a possibilidade da impossibilidade da própria existência. A morte é individual, ainda que sejamos atingidos pela morte, cada pessoa tem que morrer a sua própria morte, pois, em sentido genuíno, não fazemos a experiência da morte dos outros, no máximo, estamos apenas "junto"(8).

O que pudemos perceber, por meio desses discursos, é que ser-mulher-com-câncer-ginecológico avançado é vivenciado de maneiras diversas, pois cada mulher apresenta emoções e sentimentos que são influenciados pelo mundo em que se encontram imersas.

Encontramos nos depoimentos de outra colaboradora a alteração do conceito que possuía sobre a doença após ter tido a oportunidade de conviver com pacientes também com diagnóstico de câncer, conforme mencionaram que:

[...] Antes de eu internar eu tinha um pensamento, aí depois que eu internei e fiquei com o pessoal que tinha câncer também, aí fui vendo que eu sou uma formiguinha. Têm pessoas que... tinha até uma... menininha [...] e ela tinha também e ela 'tava lá então... eu não posso reclamar, não.'[...] Antes, eu ficava assim: "Ah, porque é um câncer, porque..." Na minha época, minha mãe, minha avó, nossa quem tinha câncer era... tinha até que bater na boca. Hoje em dia não. A medicina 'tá bem avançada e tal, mas eu não tinha contado direto com as pessoas que tinham a doença, e eu tendo eu vi que... é mais um caso, mas que o meu 'tá... porque tem gente bem pior. (Lisa) 
A mulher lançada no mundo portadora de câncer colocase adiante de si mesma e defronta-se com a possibilidade mais própria, irremissível e insuperável, no curso de seu ser, a morte. Tem incertezas quanto à possibilidade de morrer ou não e isto, certamente, gera angústia.

Angustiar-se é próprio do ser humano, faz parte da estrutura do ser da pre-sença, é na angústia que a pre-sença põe-se frente a si-mesmo. Contudo, as pessoas raramente vivem a angústia de forma própria, pois no cotidiano a presença está absorvida no mundo, esquecida de si-mesmo. O impessoal ocupa-se em reverter a angústia com a morte em temor frente à mesma, que é um acontecimento certo que virá. Além disso, considera-se a angústia, que no temor se torna ambígua, uma fraqueza que a segurança da pre-sença deve desconhecer ${ }^{(8)}$.

[...] Eu só peço a Deus que se eu tivé... que se for... tenho certeza, que Ele vai me curar, mas se tiver que me levar embora, então me leve sem sofrimento. Que eu morra até dormindo, p'ra mim não sentir tanto. (Sil)

Com certeza existe um momento em que as mulheres têm consciência de seu estado de saúde entendendo que o único desenlace possível é a morte, como ocorre com algumas depoentes desse estudo. Por isso, há, muitas vezes, uma reação de revolta, desespero ou angústia, algumas, porém, podem viver um estado de aceitação com conseqüente serenidade emocional, serenidade esta que significa descansar no ser. Acreditamos que a forma com que as pessoas enfrentam a morte relaciona-se com o sentido que dão à vida, como se pode observar nas falas abaixo:

Quanto tempo eu tenho... é simples. Quanto tempo eu tenho de vida? Fiz esta pergunta.- Ah, não sei. Quanto eu quiser. Quanto eu me esforçar. Acho que esta é a resposta. Quanto tempo eu tenho de vida? -Olha! Quem sou eu p'ra dizer quanto tempo tem de vida. O médico não sabe quanto tempo ele tem de vida, ele pode tropeçar ali e morrer. [...] Ele não vai estar mentindo. Ele não sabe quanto tempo o paciente...[...] eu estava conversando até com outro médico e não sabe [...] ninguém sabe. $E$ de paciente p'ra paciente o tamanho do tumor não significa nada, o estágio não significa nada, de paciente p'ra paciente muda e muda porque? Muda por causa da família, muda por causa da vontade de viver. Tá legal! Você tem mais um ano de vida. Eu ia sair desesperada. [...] Acho que este tempo de vida está dentro da gente. E acho que o médico tem que fazer a gente buscar este tempo de vida dentro da gente. -Vai à luta! Se arrume. Fique cheirosa. -Quanto tempo eu tenho de vida, doutor? -Não sei. Você quer quanto tempo de vida? Você acha que precisa de quanto tempo de vida? Vai à luta. (Sol)

Porque na verdade a minha mãe teve [...] mas não foi do câncer que ela morreu. Deu um derrame... morreu de outra coisa... acho que não tem nada a ver, pode me levar de outra coisa, porque aqui eu vou ficar muito tempo ainda (risos). (Rosa)
A morte é o término do projeto da pre-sença de ser simesmo, é um fato insuperável. No entanto, a mulher deve tanto enfrentar a morte, enquanto uma possibilidade da impossibilidade de seu ser, quanto enfrentar a vida. É inevitável que a mulher, enquanto ser-lançado-no-mundo em uma situação de doença, necessite de audácia para viver e morrer, ou seja, para ser e deixar de ser.

\section{A BUSCA DESAFIANTE DE UM CAMINHO PARA AGIR}

Apoiando-nos no referencial filosófico de Martin Heidegger, procedemos a análise e a interpretação das vivências verbalizadas nos discursos das mulheres e, com isso, iluminaram-se facetas destes fenômenos. Não contestamos que, ante o nosso envolvimento com a temática, sentimo-nos fragilizadas com o expresso nas descrições destas pessoas, mas o anseio em compreender o significado de suas experiências constituiu-se no alento que nos impulsionou caminhar ao encontro da possibilidade de desvelar o que ignorávamos.

A partir do olhar da mulher foi-nos permitido alcançar o sentido do ser-mulher, não como algo acabado, mas como um ser de possibilidades, mesmo diante de uma situação factual que é o convívio com o câncer ginecológico avançado. Apreendemos que ser mulher vivenciando o câncer ginecológico é oscilar entre o existir autêntico e a tranqüilidade da existência inautêntica. Neste estudo desvelou-se que ser-mulher-com-câncer-ginecológico avançado é ter o seu modo de ser-no-mundo influenciado pelas modificações em sua imagem corporal decorrentes do estar-com-câncer e do tratamento a que se submete; é buscar transcender considerando as restrições impostas pela doença como uma possibilidade; manifestar sentimentos contraditórios em relação à solicitude; sentir angústia e temor fugindo, assim, à condição existencial de ser-para-a-morte.

Conhecendo, agora, a essência dos fenômenos, reafirmamos que os mesmos referem-se à questões existenciais permitindo-nos vislumbrar caminhos para cuidar da mulher-comcâncer-ginecológico avançado. Consideramos que o cuidado de enfermagem a estas pessoas ultrapassa as intervenções pautadas somente em aspectos técnicos e no saber biológico. É necessário, pois, compreender o vivido pelas mulheres, abandonando a concepção do cuidado a partir apenas da perspectiva de quem cuida, e integrar nesta também a visão de quem é cuidado. O cuidar desenvolvido pela enfermeira precisa constituir-se em um encontro fenomenológico entre a pessoa que é cuidada e a que cuida, sendo este encontro mediado pela relação com o outro, percebidos em sua totalidade, tal como se mostram ou se dão a perceber.

Consideramos primordial esta questão para o ensino e a prática de enfermagem, pois é evidente a necessidade em se assegurar o cuidar com habilidade técnica e na dimensão 
biológica, mas é fundamental contemplar, também, a subjetividade e a intersubjetividade. A enfermeira necessita envolver-se não apenas no controle de sintomas físicos, mas assistir à área expressiva, e isso requer um diálogo dentro de um contexto de empatia, aceitação, envolvimento emocional, utilizado habilidades de comunicação. Isto implica em incorporar um ato de cuidar abrangente sustentado no referencial do relacionamento interpessoal, ou seja, agregando às ações cuidativas em enfermagem a atenção e o comprometimento para com o outro.

Esta pesquisa dá-nos condições para refletir, não só junto aos alunos, mas também junto às enfermeiras uma forma de pensar, sentir e de agir diversa desta que se tem observado. Almejando realizar a devida articulação entre a academia e o serviço de saúde, avaliamos que essas reflexões, presentes neste estudo, podem e devem ser empregadas na prática assistencial mediante o modo de ser das enfermeiras, que atuam na oncologia. Acreditamos, portanto, que outro compromisso que temos a assumir é investir no aperfeiçoamento das enfermeiras para que possam buscar compreender o cuidado como estrutura fundamental do seu ser, tal como é

\section{REFERÊNCIAS}

(1) Silva ARB. A experiência de enfermeiras no cuidado de mulheres com câncer ginecológico avançado [dissertação]. São Paulo: Escola de Enfermagem da USP; 1997.

(2) Praça NS, Merighi MAB. Abordagens teórico-metodológicas qualitativas: a vivência da mulher no período reprodutivo. Rio de Janeiro: Guanabara Koogan; 2003. Pesquisa qualitativa em enfermagem; p. 1-3.

(3) Capalbo C. Abordando a enfermagem a partir da fenomenologia. Rev Enferm UERJ. 1994;2(1):70-6.

(4) Merighi MAB. Fenomenologia. In: Merighi MAB, Praça NS. Abordagens teórico-metodológicos qualitativas: a vivência da mulher no período reprodutivo. Rio de Janeiro: Guanabara Koogan; 2003. p. 33-7. abordado por Heidegger. E, assim, tenham a possibilidade de manifestá-lo consigo mesma e em solicitude com o outro, enquanto processo de abertura, para que tanto elas como as pacientes possam transcender o seu próprio ser, alcançando a sua própria verdade. Deste modo, sabemos que é chegado o momento de compartilhar com as enfermeiras o que até aqui temos refletido buscando estar junto repensando as relações pessoais na equipe de trabalho e o compromisso para com o cuidado, que não seja superficial e nem indiferente, mas um cuidar autêntico.

O desafio que nos propomos, então, enfrentar é pesquisar, aprender e ensinar o cuidar, numa dimensão existencial. Para tanto, pretendemos nos aprofundar no estudo da fenomenologia, pois este referencial pode fornecer subsídios relevantes para o repensar do ensino e da prática de enfermagem. Acreditamos que novas pesquisas à luz da filosofia de Martin Heidegger incluindo temas do ensino e do assistir em enfermagem possam ser viabilizadas, ainda mais por que, na ótica existencialista, o significado do ser não é algo acabado, pois os fenômenos não se esgotam em uma perspectiva, mas se modificam a cada olhar.

(5) Brasil. Ministério da Saúde. Instituto Nacional do Câncer. Coordenadoria de Programas de Controle do Câncer-Pro-Onco. TNM: classificação dos tumores malignos [online]. Rio de Janeiro: INCA; 2001. Disponível em: <http.www.inca.org.br/tratamento/tnm/> [Acesso em 31 jul 2001].

(6) Josgrilberg RS. O método fenomenológico e as ciências humanas. In: Castro DSP, organizador. Fenomenologia e análise do existir. São Paulo: Universidade Metodista de São Paulo; 2000. p.75-93.

(7) Heidegger M. Ser e tempo. Trad. de Márcia de Sá Cavalcante. $7^{a}$ ed. Petrópolis: Vozes; 1998. (Coleção Pensamento Humano, parte I).

(8) Heidegger M. Ser e tempo. Trad. de Márcia de Sá Cavalcante. $6^{\text {a }}$ ed. Petrópolis: Vozes; 1998. (Coleção Pensamento Humano, parte II). 